\title{
Formation of Gradient Micro-Porous Titanium-Aluminides Through Elemental Powder Metallurgy
}

\author{
Cynthia Kornegay Waters, Gerald Ross Vosburg, Stephen Ajinola
}

Mechanical Engineering, North Carolina A\&T State University, Greensboro, NC, USA

\section{Email address:}

kwaters@ncat.edu (C. K. Waters)

\section{To cite this article:}

Cynthia Kornegay Waters, Gerald Ross Vosburg, Stephen Ajinola. Formation of Gradient Micro-Porous Titanium-Aluminides Through Elemental Powder Metallurgy. International Journal of Materials Science and Applications. Vol. 7, No. 2, 2018, pp. 33-38.

doi: $10.11648 /$ j.ijmsa.20180702.11

Received: May 31, 2017; Accepted: June 12, 2017; Published: January 18, 2018

\begin{abstract}
The research into alloys, specifically titanium and aluminum alloys (Ti \& Al), has rapidly growing technological importance. The combined research into Ti-Al alloys in the field of powder metallurgy has advanced the fabrication of a part with high compressive strength, low relative density and material properties in addition to being a cost-effective process. In this work Ti-Al alloys were created using elemental $\mathrm{Ti}$ and Al powders. Elemental powders with a melting point of over $1000^{\circ} \mathrm{C}$ were sintered via liquid phase sintering (LPS). LPS is a process used for forming high performance, multiple-phase components from powders. It involves sintering at a temperature between the melting points of the two powders. The structural morphology, pore size and location were evaluated using Scanning Electron Microscopy (SEM) and optical microscopy. These methods allowed visible evidence of structural anomalies providing a capillary action which pulled the liquid $\mathrm{Al}$ to the surface and resulted into a densification of the part at the surfaces. The dense structure was seen on both the top and bottom of the samples with a layer of predominantly Al. The average on the top surface layer using optical measurements was $0.48 \mathrm{~mm}$ and the bottom was $0.97 \mathrm{~mm}$.
\end{abstract}

Keywords: Powder Metallurgy, Capillary Action, Ti, Al, Alloys, Wicking

\section{Introduction}

The development of powder metallurgy and its applications can be traced to 3000 B.C. [1] when it is believed that civilizations began by making items based on the principles of powder metallurgy. The Egyptians of the $12^{\text {th }}$ century BC displayed knowledge of carburization of iron at the end of the Bronze Era with the addition of the quenching technique in the $9^{\text {th }}$ century BC to harden the steel they created. Daggers with gold powder inlaid were found in the tomb of the well-known Egyptian Pharaoh Tutankhamun. In the $11^{\text {th }}$ century Arabs and German blacksmiths used iron powders to infuse into the steel lumps where the steel was exposed to oxide corrosion (commonly known as rust). What the early powder practitioners knew was that packed powder heated to just below their melting temperature formed the powders together. This process is called sintering. We know that atomic solid-state diffusion increases exponentially with temperature and sintering used the mechanism of diffusion to form a bond between the contact particles. Sintering can occur over a range of temperatures, but is hastened as different powders acquire more energy as they approach their melting points. It takes place faster as the particle size decreases since diffusion distances are shorter and curvature stresses are larger. When powders are selected with a wide variance in their melting points they become candidates for liquid phase sintering (LPS). In this heated energetic state, more refractory powders are soluble in the lower melt point powder that has formed the liquid and causes the liquid to wet the solid, providing a capillary force that pulls the grains together [2-3]. Typically, liquid phase sintering begins by mixing two or more small powders of differing compositions [4]. On heating, powder melts or reacts to form a liquid that fills in between the remaining solid particles hence engulfing the more refractory phase. If the particle size is small, then capillary forces from the wetting liquid enhance densification [5]. Kim et.al. recently presented work in which they prepared porous $\mathrm{Ti}$ by a metal injection molding (MIM) process, and the pores in the Ti were filled with molten Al. They first created the porous $\mathrm{Ti}$ and then infiltrated the 
second elements for short times (30e120 s), and were able to obtain reinforced Ti composites having near-net shape [6].

\section{Methods}

This work consisted of intersecting steps including solidstate diffusion, particle rearrangement, solutionreprecipitation, and solid skeleton densification shown in Figure 1. The final structure can be described as a metalmetal composite of grains originally solid during sintering entwined with the now solidified liquid post sintering.

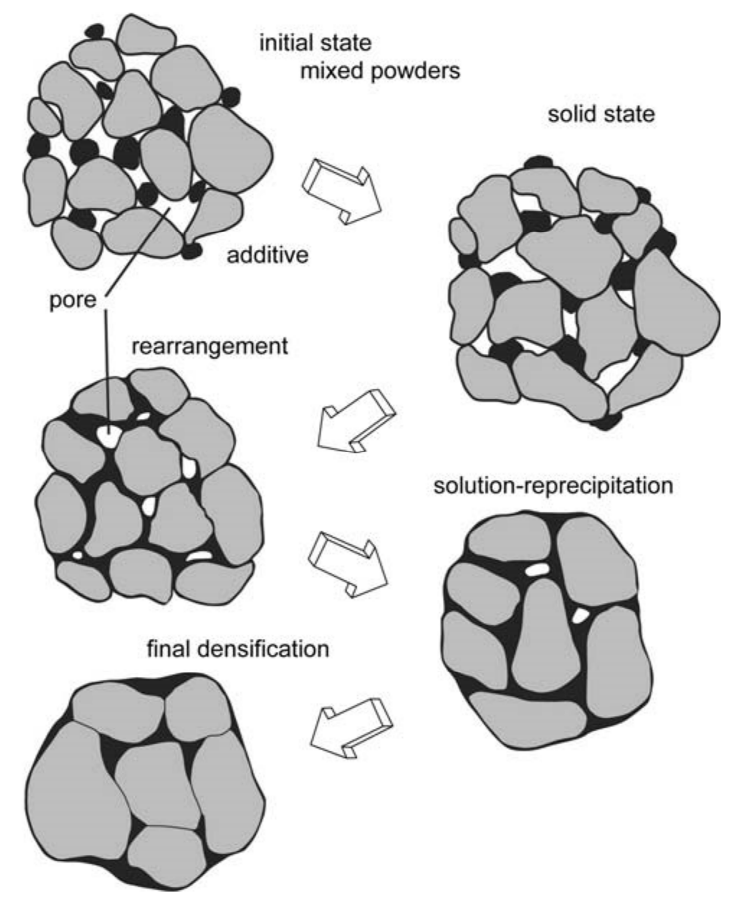

Figure 1. Schematic progression of LPS microscopic changes starting with mixed powders and pores between the particles. During heating the particles sinter, and when a melt forms and spreads the solid grains rearrange. For many products there is pore annihilation as diffusion in the liquid accelerates grain shape changes that facilitates pore removal to produce a composite microstructure with custom-made properties. [4]

Wettability in infiltration is also dependent on the properties of the porous scaffold. The liquid phase provides optimal wetting when the particles are small. The wettability of a porous scaffold is subject to factors including the chemical composition of the reinforcing material, and its surface roughness, although it can be assumed that if $\mathrm{Ra}<10$ $\mathrm{nm}$, then the impact of roughness on the wetting angle is irrelevant [7]. It is also dictated by the scaffolds' porosity, because porosity above $5-8 \%$ of volume is reducing the wetting angle associated with the penetration of liquid metal inside the pores. The materials chosen for this work were Ti and $\mathrm{Al}$ elemental powders. $\mathrm{Ti}$ is the $9^{\text {th }}$ most abundant element and the $4^{\text {th }}$ most abundant metal in the Earth's crust, $\mathrm{Al}$, iron and magnesium being more abundant [8]. $\mathrm{Ti}$ is seldom found in high concentration and cannot be found in a pure ore state. Processing $\mathrm{Ti}$ is expensive and is only produced in batches and not in a continuous process as with other metals therefore making it a valuable candidate for additive manufacturing processes. It is commonly found as ilmenite $\left(\mathrm{FeTiO}_{3}\right)$ or rutile $\left(\mathrm{TiO}_{2}\right)$, Ti dioxide is used wildly as a white pigment in paper, plastics and paint. There are two types of pure Ti depending on the temperature of the element, $\alpha$-Ti occurs when the temp is below $882^{\circ} \mathrm{C}$ with a Hexagonal Close Packed structure (HCP) and $\beta$-Ti when it is between $882^{\circ} \mathrm{C}$ and $1670^{\circ} \mathrm{C}$ with a body-centered cubic (BCC) crystal structure. Ti's significance lies in its high strength-to-density ratio and its remarkable corrosion resistance [9]. It is a structurally effective metal used in high-performance aircraft, spacecraft, chemical industry, medical engineering [10] and in the leisure sector.

Al has many attributes that have a wide range of applications such as: good corrosion resistance, high electrical and thermal conductivities, low density (2.70 $\mathrm{g} / \mathrm{cm}^{3}$ ), high reflectivity, high ductility and reasonably high strength all at a relatively low manufacturing cost [11]. Al has a moderately low melting point of $655^{\circ} \mathrm{C}$ and a facecentered cubic crystalline structure. Because of these properties $\mathrm{Al}$ and its alloys are used in many consumer products as well as medical, military, transportation [12], aerospace and marine industries. Ti-Al alloys are very adaptive in military, transportation, aerospace [13], marine and medical disciplines. Figure 2 shows the phase diagram of $\mathrm{Ti}$ and $\mathrm{Al}$ by weight and atomic percentage which includes over a $100 \mathrm{Ti}$-Al based alloys with a wide array of properties.

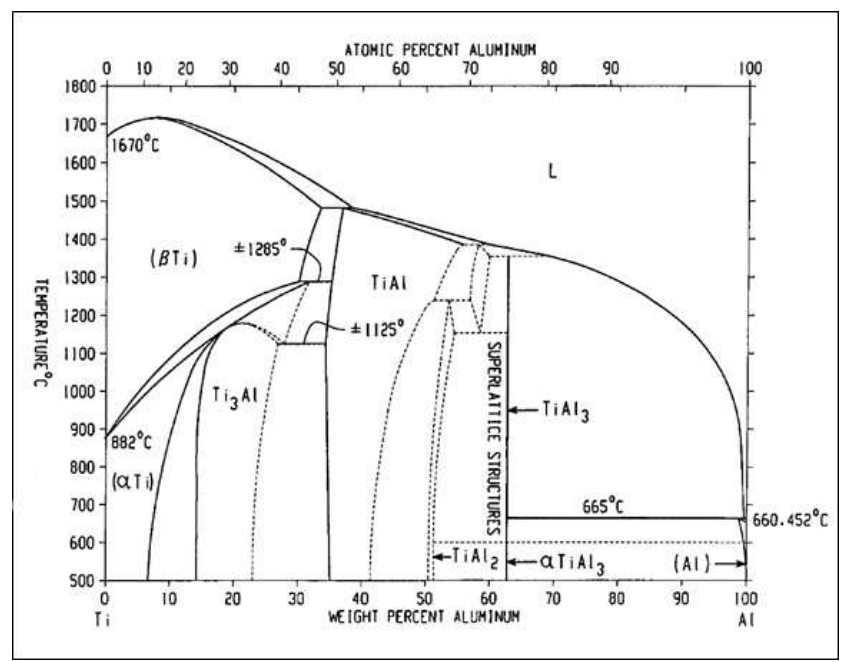

Figure 2. Ti-Al phase diagram.

With the scarcity of resources for an ever-growing population with increasing demands for passenger and goods transportation from country to country, the aerospace industry invests a large amount of time into the research of Ti-Al alloys. Due to the higher ratios of energy consumption to weight for air transportation vs a similar comparison for ground transportation and an ever-ongoing search for lighter and durable materials for use in the aerospace industry is needed. The last decade has seen the importance in Ti-Al alloys in the aerospace industry and the industrial sector has increased its research into the alloys.

The intent of the process was to create porous gradient 
alloy metals through the BE powder metallurgy. Elemental Ti and $\mathrm{Al}$ powder were both purchased from Atlantic Equipment Engineers. The powders were sieved using a 250 mesh size. The total mass of the samples was altered slightly but the weight percentage was maintained. The mixing procedure was conducted using mortar and pestle. Prior work has found that variables of green die pressure, soaking temperature, soaking time, weight percentage of each metal powder is critical. After consideration a uniaxial die pressure of $2.7 * 108 \mathrm{~N} / \mathrm{m}^{2}$ was utilized and used for all the samples. Following the mixing of the samples, individual batches were pressed in a uniaxial press bought from Carver Incorporation to form a green samples discs at the size of $25 \mathrm{~mm}$ diameter.

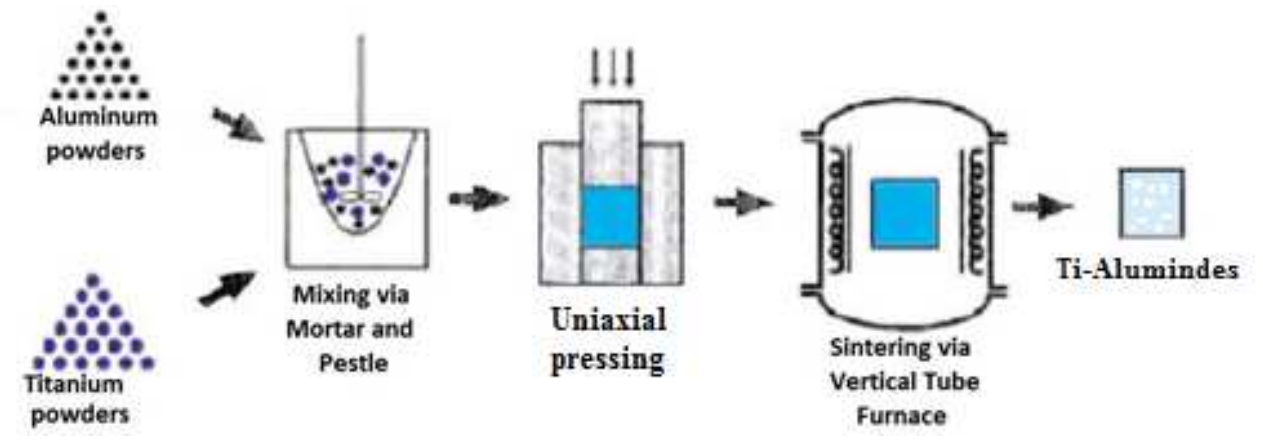

Figure 3. Schematic model of experimental process.

For the powder process alloy development analysis of $\mathrm{Ti}$ and $\mathrm{Al}$ alloying the variables that directly affect the outcome are temperature and soak time. These factors are primary in the diffusion mechanism that creates the alloys. Two temperatures, $1000^{\circ} \mathrm{C}$ and $1300^{\circ} \mathrm{C}$ and two different soak times of 5 hours or 15 hours were chosen and the heating curves are shown in Figure 4. These were selected based on the phase diagram examination. A decision was made to eliminate binder from the process due to the fact that $\mathrm{Al}$ powders will mold around with the Ti powders and thus would not need a binder. Ti-50Al and Ti-8Al by weight percentage samples were created for the sintering process. The vacuum furnace was sealed prior to heating and purged with argon. The ramp rate was 10 degrees per minute while the cooling was done by cooling down naturally in the furnace.

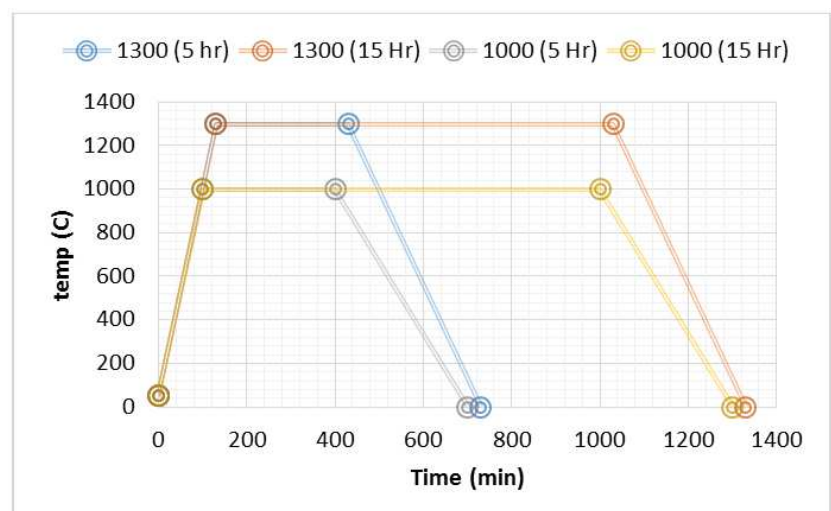

Figure 4. Heating chart for sintering 4 different samples. Ramp up rate was 10 degrees per min and cool down rate was a natural cooling rate.

Once samples were sintered all samples were cut into three sections using the diamond blade precision saw so that each face could be ground and polished. Then selected samples were etched using the Krolls solution. Samples were inspected via the optical microscope or the Hitachi SU-8000
FE-SEM for analysis of the microstructure, sintering integrity and porosity.

\section{Results and Discussion}

In both the $\mathrm{Ti}-50 \mathrm{Al}$ and $\mathrm{Ti}-8 \mathrm{Al}$ samples the resulting morphology provides evidence that capillary action occurred which resulted in wicking of liquid aluminum towards the extremities of the sample. The samples were porous as intended yet the porosity varied with sample location. Capillary action, or wicking, is defined as the act to move moisture by capillary action from the inside to the surface. Gravity also has an effect on capillary action as shown in Figure 5.

Due to the wicking a non-uniform distribution of Al was present within the samples. The al heavily migrated towards the exterior of the sample. This also resulted in the formation of oxides predominately $\mathrm{Ti}$ oxides to form in the center of the samples. These oxides are very difficult to sinter and resulted in metal-ceramic composites that were not wanted in the center of the samples. This result was not focused on in this paper.

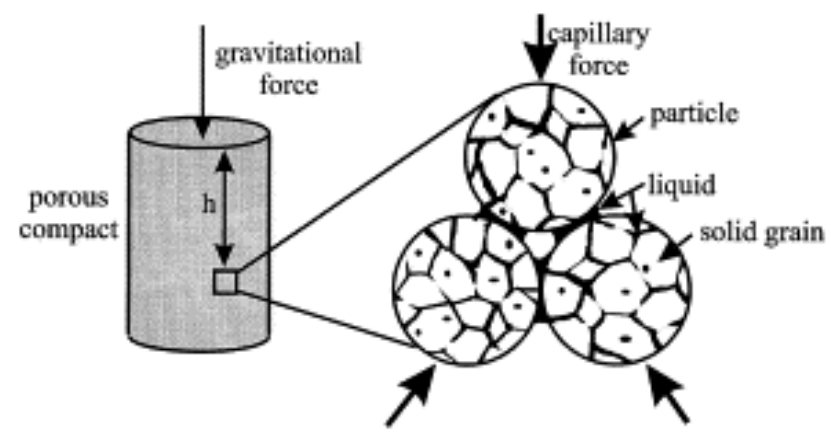

Figure 5. Capillary action on porous compacts diagram.

The morphology of the green pressed powder samples was such that a size variation of pores existed in the samples 
which were then subjected to capillary action when sintering occurred in the LPS regime. Both the Ti-50Al and Ti-8Al were heated in this manner. The size of the pre-sintered pores can be modeled such that the average pore radius is $r_{p}$ and is equal to $r$ in Figure 6 . This means that there is an inverse relationship between average pore size and the magnitude of the capillary force wicking the liquid phase towards the extremes. In the current model the molten $\mathrm{Al}$ is the nonaqueous phase liquid (NAPL).

$$
P_{c}=P_{N}-P_{A}=-\frac{2 \sigma}{r}
$$

$\sigma=$ NAPL-air interfacial tension $($ dyne $/ \mathrm{cm})$

$\mathrm{r}=$ pore throat radius $(\mathrm{cm})$

$\mathrm{P}_{\mathrm{c}}$ is the capillary pressure,

$\mathrm{P}_{\mathrm{N}}$ is the NAPL tension and $\mathrm{P}_{\mathrm{A}}$ is the air tension

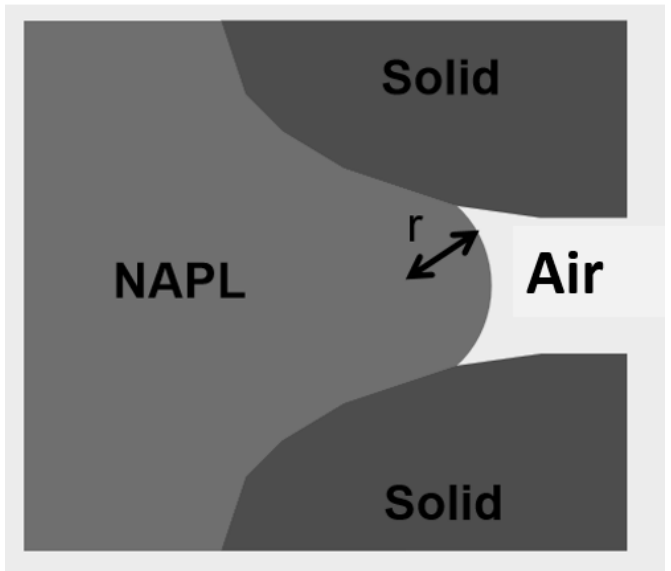

Figure 6. Model proposed to explain capillary effect and resultant wicking of molten Al into pore space of the Ti during sintering.

In Figures 7-10 the resultant morphologic structure from capillary action is evident on the edges, predominately the top and bottom of the samples. This action occurred because of elemental powder process LPS. The difference in melting points allows for LPS of Al combined with Ti to occur when the entire green form was heated above Al's melting point. The extremities of the sample would always reach equilibrium temperature prior to the center. The Al from the surface of the sample melts first causing a chain of melting and wicking that pulled the molten $\mathrm{Al}$ from the center to the surface of the sample. In all of these images one could see there were defined boundary regions both on the top and the bottom to the sample. In most of the samples the thickness of the regions showed variance which can be explained by wicking resulting from the capillary pressure of Eq. 1 in addition to the gravitational force. In figure 9 a crack is evident on the left of the image due to cooling forces and material size differences. On the top of the sample the forces act in opposition to each other and on the bottom they act in concert. The compositional analysis via EDS confirmed the high concentration of Aluminum in the denser regions. The sample prior to sintering is confirmed to have uniformly distributed powders of Ti and Al.

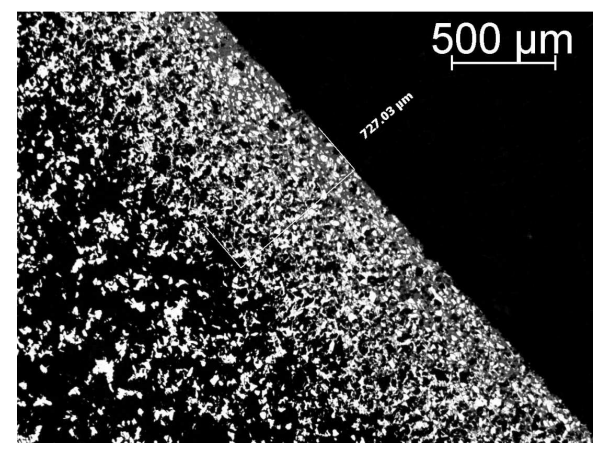

Figure 7. Ti-8Al wicking on bottom of sample when sintered.

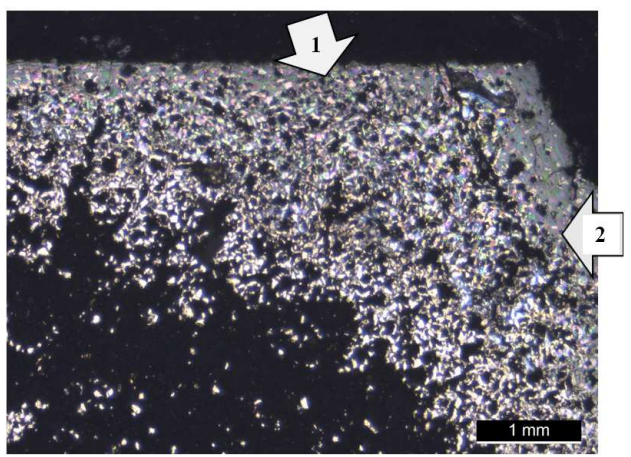

Figure 8. Wicking example of bottom of sample (1) and side of sample (2) when sintered.

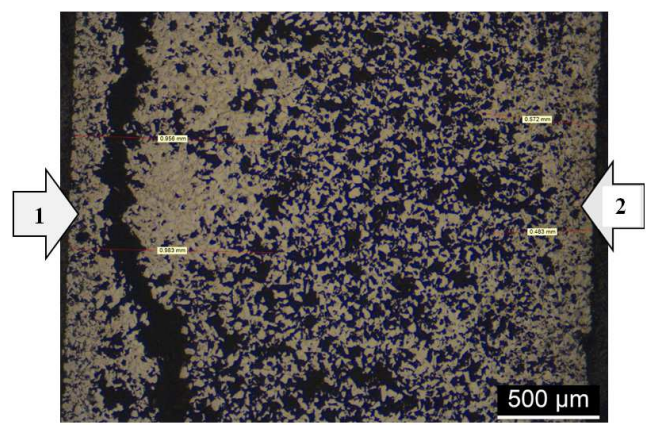

Figure 9. Wicking of top of the sample (2) compared to the bottom of the sample (1) when sintered.

Samples made at Ti-50Al weight percent did see wicking occur at the surface. Shown in Figure 10. A more defined boundary can be seen due to the larger amount of $\mathrm{Al}$ in the system.

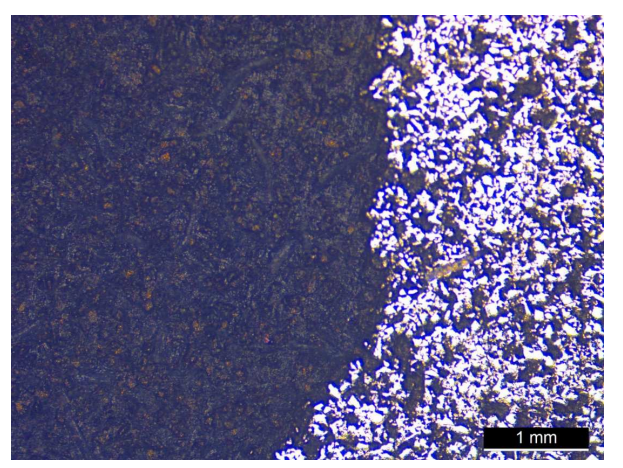

Figure 10. Optical micrograph displaying wicking occurring in Ti-50Al weight percent produced larger and more defined boundaries. 
Further microstructure analysis, SEM, and EDS analysis were run for confirmation of diffusion and phases present within the Ti-50Al sample sets. Figure 11 displays a polished and etched set of images. This showed the presence of some remaining porosity and the presences of various $\mathrm{Ti}-\mathrm{Al}$ alloys. On samples of Ti-50Al the microstructures of TiAl, Ti $(\alpha)$, $\mathrm{TiAl}_{3}$, are present. Figure 12 shows the elemental concentrations of titanium and aluminum in the sample.

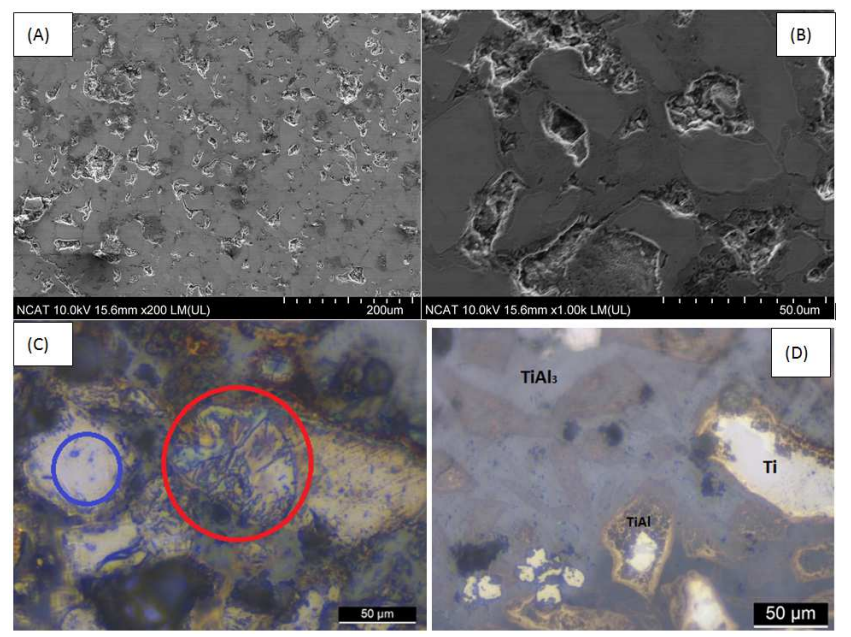

Figure 11. Ti-50Al samples. $A$ and $B$ or SEM images and $C$ and $D$ are optical micrographs. TiAl phase is circled in red and titanium $(\alpha)$ is circled in blue.
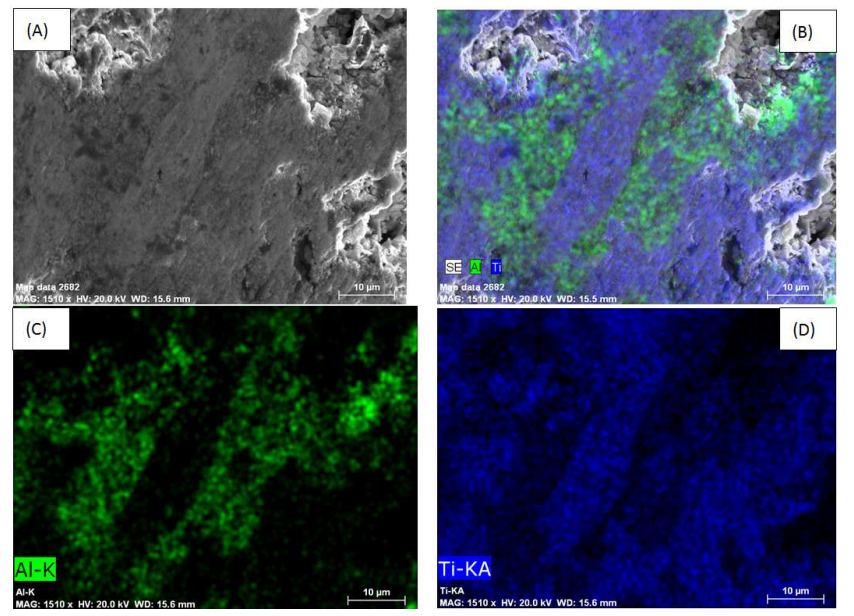

Figure 1. EDS hypermap analysis of liquid phase aluminum in between titanium particles. SEM image (A) from near the surface. hypermap (B) aluminum $(C)$ and of titanium (D).

\section{Conclusion}

The development and optimization of Ti and Al gradient alloys were partially successful by mixing the $\mathrm{Ti}$ and $\mathrm{Al}$, followed by pressing in a uniaxial press die of a constant pressure. Sintering of the samples was successfully conducted in an argon environment which culminated in the creation of alloys. Residual oxygen was difficult to eliminate which resulted in the growth of $\mathrm{Ti}$ and $\mathrm{Al}$ oxides that could not be removed and causing undesirable metalceramic composites. The development of non-uniform layers of densification due to capillary action were evident confirming that wicking had occurred. The top surface layer of the samples averaged a thickness of $0.48 \mathrm{~mm}$ while the bottom layer was $0.97 \mathrm{~mm}$. The bottom layer was twice as thick as the uppermost layer and this difference was consistent with all the samples. This difference was hypothesized to be due to the addition of gravity to the capillary pressure $P_{c}$ since all samples tested reflected these results. Capillary action therefore can be said to be a result in LPS samples when using the BE powder metallurgy process. Research into this result could be utilized for future $\mathrm{BE}$ powder samples and additive manufacturing. Additive manufacturing will be highly effected by these results when sintering for full densification for maximum strength due to higher than wanted porosity in the center of the structure resulting in areas for stress concentration.

\section{Acknowledgements}

This study was funded by NASA Space Grant \# 12-0352

\section{References}

[1] Ramakrishnan, P., "History of Powder metallurgy", Indian Journal of History of Science, 18(1): 109-114, (1983).

[2] Eustathopoulos, N. \& Voytovych, R., "The role of reactivity in wetting by liquid metals: a review" J Mater Sci, 51: 425, (2016).

[3] Manu, K. S., Raag, L. A., Rajan, T. P. D., Gupta, M., \& Pai, B. C., "Liquid Metal Infiltration Processing of Metallic Composites: A Critical Review", Metallurgical and Materials Transactions B, 47(5), 2799-2819, (2016).

[4] German, R. M., Suri, P., \& Park, S. J. "Review: liquid phase sintering", Journal of Materials Science, 44(1), 1-39. (2009).

[5] Hwang, K. S., German, R. M., and Lenel, F. V., "Capillary Forces Between Spheres During Agglomeration and Liquid Phase Sintering," Metall. Trans., vol. 18A, pp. 11_17, (1987).

[6] Kim, S., Kim, G., Lee, W., Lee, H. S., Jeung, W., “A novel method to fabricate reinforced Ti composites by infiltration of Al (Mg) into porous titanium", Journal of Alloys and Compounds, Volume 715, Pages 404-412, (2017).

[7] Dobrzański, L., Matula, G., Dobrzańska-Danikiewicz, A., Malara, P., Kremzer, M., Tomiczek, B., Kujawa, M., Hajduczek, E., Achtelik-Franczak, A., Dobrzański, L., Krzysteczko, J., "Composite Materials Infiltrated by Aluminium Alloys Based on Porous Skeletons from Alumina, Mullite and Titanium Produced by Powder Metallurgy Techniques", Powder Metallurgy - Fundamentals and Case Studies, Chapter 5, published by Intech, (2017).

[8] Peters, M., Hemptenmacher, J., Kumpfert, J., \& Leyens, C., Structure and Properties of Ti and Ti Alloys Ti and Ti Alloys (pp. 1-36): Wiley-VCH Verlag GmbH \& Co. KGaA. (2005).

[9] Guide, T. A., RMI Ti Company an RTI International Metals. Inc. Company. (2000). 
[10] Torres, Y., Lascano, S., Bris, J., Pavón, J., \& Rodriguez, J. A., Development of porous $\mathrm{Ti}$ for biomedical applications: A comparison between loose sintering and space-holder techniques. Materials Science and Engineering: C, 37, 148155. (2014).

[11] Campbell, F. C., Elements of metallurgy and engineering alloys. Materials Park, Ohio, (2008).
[12] Huo, S., Heath, B., \& Ryan, D., Applications of Powder Metallurgy Als for Automotive Valve-Trains., (2008).

[13] Henriques, V. A., Bellinati, C. E., \& da Silva, C. R., Production of Ti-6\% Al-7\% Nb alloy by powder metallurgy (P/M). Journal of Materials Processing Technology, 118(1), 212-215., (2001). 